\title{
Análise de livros infantis para a promoção de desenvolvimento sociocognitivo em pré-escolares ${ }^{1}$
}

\author{
Analysis of children's books for the promotion \\ of socio-cognitive development in pre-school infants
}

\author{
Marisa Cosenza RODRIGUES ${ }^{2}$ \\ Paula Almeida de OLIVEIRA ${ }^{3}$
}

\begin{abstract}
Resumo
Considerando a necessidade de uma atuação mais pró-ativa dos psicólogos escolares, este estudo teve como objetivo analisar, com foco no processamento de informação social, uma amostra de cem livros de histórias infantis nacionais dirigidos a pré-escolares de 4 a 6 anos. Os livros foram analisados considerando a ocorrência dos seis componentes de um programa estadunidense de redução do comportamento agressivo por meio de histórias infantis. Os resultados mostraram que 32\% dos livros apresentaram um repertório relevante e 47\% evidenciaram um repertório significativo de pistas sociais, apontando para a viabilidade da utilização dos livros infantis nacionais como recurso para promover o desenvolvimento sociocognitivo e prevenir comportamentos agressivos e antissociais no contexto educativo.
\end{abstract}

Unitermos: Processos cognitivos. Literatura. Psicologia educacional.

\begin{abstract}
In view of the need for a more proactive involvement from school psychologists, this study aimed to analyze, based on a social information processing approach, a sample of 100 children's books aimed at preschool children aged between 4 and 6 years. The books were analyzed by considering the occurrence of the six components of an American program for the reduction in aggressive behavior through children's storybooks. The results showed that $32 \%$ of the books offered an excellent repertoire and $47 \%$ evidenced a significant repertoire of social traces, pointing to the viability of the use of national storybooks for children as a resource for promoting socio-cognitive development and preventing issues concerning aggressive and anti-social behavior in the educational context.
\end{abstract}

Uniterms: Cognitive processes. Literature. Educational psychology.

O sistema educacional no Brasil tem apresentado inúmeros problemas que acarretam graves consequências sociais: crianças fora da escola, dificuldades de aprendizagem, evasão, marginalização e violência (Guzzo, 2003), além de manifestações socioemocionais encontradas em uma elevada porcentagem de crianças (Elias, 2003).

Segundo Guzzo (2003), a psicologia escolar deve responder ao desafio de impactar o sistema educacional pela ação profissional, em uma perspectiva de prevenção

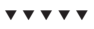

1 Apoio Financeiro: Conselho Nacional de Desenvolvimento Científico e Tecnológico. Processo 2005/1119.

2 Universidade Federal de Juiz de Fora, Instituto de Ciências Humanas e Letras, Departamento de Psicologia. Campus Universitário, Martelos, 36015-400, Juiz de Fora, MG, Brasil. Correspondência para/Correspondence to: M.C. RODRIGUES. E-mail: <rodriguesma@terra.com.br>.

3 Psicóloga. Juiz de Fora, MG, Brasil. 
de problemas socioemocionais e para a promoção da saúde psicológica. Desse modo, o psicólogo deve mudar o enfoque de ação, habilitando-se para trabalhar com políticas públicas, conscientizar pais e professores sobre necessidades básicas de crianças e adolescentes e mobilizar a comunidade educacional, utilizando recursos da comunidade, em torno de uma proposta de intervenção.

Nessa perspectiva de atuação, que privilegia a prevenção e a promoção da saúde e o bem-estar subjetivo, a autora salienta ainda que a eficácia do sistema escolar depende do quanto este sistema é capaz de manter crianças com prazer e motivadas a estudar e aprender, do quanto é capaz de fazer a criança evoluir, crescer, tornar-se competente e resiliente às demandas de sua vida. Espera-se que o psicólogo compreenda a importância de seu trabalho neste campo, sempre integrado com outros setores que possam interferir no desenvolvimento da criança, sobretudo a família e a comunidade.

Araújo e Almeida (2003) reafirmam essa prática, apontando que o psicólogo escolar/educacional deve exercer sua função adotando abordagens teóricas que sustentem as ações a serem desenvolvidas, refletindo sobre sua realidade e promovendo o desenvolvimento do aluno. Para tanto, faz-se necessário o redimensionamento da prática dos psicólogos escolares, que, segundo autores como A. Del Prette e Z. A. Del Prette (2003), Feldman (1994) e Guzzo (2003), constitui um exercício cada vez mais importante tanto quanto urgente e possível, considerando a realidade educacional sul-americana.

Dentre as inúmeras possibilidades de intervenção e atuação, Elias e Marturano (2005) apontam como estratégia possível as oficinas de linguagem, que constituem modalidade de intervenção para crianças com queixas escolares, tendo por meta ajudá-las a desenvolver um senso construtivo de autoeficácia para as tarefas, além de ter um efeito positivo de redução de tensões emocionais e problemas de comportamento, comuns em crianças com dificuldades acadêmicas. Com foco em uma intervenção proativa, Rodrigues $(2004,2005)$ defende a contribuição de teorias e modelos psicológicos de domínio específico, como a abordagem do processamento de informação social destacando, mais especificamente, o modelo de processamento de informação social de Dodge e Crick (1994), cuja ênfase é a adaptação psicossocial de crianças e adolescentes.

Sob a ótica cognitivista, vários recursos e tecnologias podem ser utilizados na prática psicológica. Neste trabalho focalizou-se a importância das histórias infantis como recurso útil tanto na promoção quanto na prevenção de comportamentos agressivos e antissociais, dado que tais comportamentos, de acordo com Z. A. Del Prette e A. Del Prette (2005), potencializam uma trajetória de risco psicossocial e acadêmico na vida das crianças.

\section{Histórias e promoção do desenvolvimento infantil}

Ao analisar o desenvolvimento da literatura infantil, observa-se que, ao longo do tempo, sua estrutura e seus objetivos foram variáveis. As perspectivas para as histórias infantis foram se alterando à medida que a visão predominante em relação ao desenvolvimento das crianças se modificava (Alves, 2001).

Estudiosos como Becker (2001) têm partido do pressuposto de que só se pode realmente falar em literatura infantil a partir do século XVII, época da reorganização do ensino e da fundação do sistema educacional burguês. Os textos produzidos para crianças deixavam transparecer os valores dessa nova classe social, valores expostos de maneira idealizada, com a intenção de promover comportamentos socialmente desejáveis nos leitores.

Em fins do século XIX, a literatura infantil chegou ao Brasil, disseminando essa mesma concepção de caráter didático, difusor de preceitos e normas comportamentais que doutrinavam as crianças. De acordo com a autora anteriormente citada (Becker, 2001), tal posicionamento veio se modificando com o desenvolvimento da psicologia da infância, instaurando-se uma linguagem simples e dirigida diretamente às necessidades e fantasias da criança, introduzindo a função lúdica da literatura.

Na visão de Saraiva (2001), a literatura infantil, por meio da leitura, conduz à autocompreensão e ao estabelecimento de relações interpessoais mais ricas, integrando o leitor ao meio sociocultural, possibilitando-Ihe tomar consciência de si e das contradições inerentes à realidade. 
Em outra ótica, Witter (2004) salienta a importância da leitura no cotidiano das pessoas como fonte de informação, lazer, realização pessoal e como forma relevante de inserção social. No que diz respeito aos amplos benefícios que a leitura de livros infantis pode proporcionar às crianças, Rodrigues (2004) afirma haver um consenso irrestrito entre os especialistas nacionais e internacionais de diferentes áreas. No entanto, a leitura como estratégia de prevenção ainda é pouco explorada e conhecida no contexto brasileiro, (Witter, 2004), embora alguns esforços possam ser evidenciados, obtendo-se resultados favoráveis, ao nível de prevenção primária, com crianças com comportamento de risco (Rodrigues, Abreu \& Carvalho, 2005).

Na perspectiva da leitura como recurso preventivo e promotor de desenvolvimento humano, é possível vislumbrar a possibilidade de se utilizar os livros de histórias infantis como fonte de compreensão do processamento de informação social e desenvolvimento de competências sociocognitivas. Estudos internacionais (Cassidy et al., 1998; Dyer, Shatz \&Wellman, 2000) demonstram que os livros de histórias para crianças pequenas, pelo conteúdo do material textual que apresentam, pelo tipo de linguagem que utilizam e por centrarem suas ações e interações em pessoas ou animais personificados, constituem fonte relevante de informações sobre estados mentais, podendo ampliar as habilidades infantis no domínio da compreensão das intenções, desejos, crenças, emoções, conhecimento de si próprio e dos outros (Rodrigues, 2004).

Desse modo, aponta-se a viabilidade da utilização dos livros infantis nacionais como recurso para prevenir comportamentos agressivos e antissociais dentro do enfoque preventivo e educacional, visto que, como salientam Z. A. Del Prette e A. Del Prete (2005), "comportamentos anti-sociais decorrem de uma multiplicidade de fatores que interagem e potencializam efeitos negativos a curto, médio e longo prazos, caracterizando uma trajetória de risco" (p.23).

O relato e a leitura de histórias contribuem de modo significativo para a ampliação da visão da realidade da criança. Os livros infantis abordam a escuta e a observação das outras pessoas na perspectiva da aprendizagem e conscientização de que os outros também possuem pensamentos, expectativas, sentimentos e motivos, e que suas ações têm consequências nas diversas situações que vivenciam.
A estrutura das histórias contidas nos livros para crianças possibilita sua utilização como ferramenta para organizar elementos importantes do processamento de informação social. No entanto, há poucos estudos analisando a importância dos livros no processo de expansão e entendimento mental. Esta é uma área que ainda precisa ser explorada, sendo imprescindível o despertar para o fato de os livros infantis constituírem um recurso potencial na promoção do desenvolvimento e da saúde mental da criança. Nesta direção concentram-se os esforços deste artigo, que pretende oferecer subsídios para a utilização das histórias infantis com foco no processamento de informação social.

\section{O processamento de informação social}

Os fundamentos conceituais para as teorias de processos mentais influenciando o comportamento social vêm da ciência cognitiva. A origem dos modelos voltados para o processamento de informação social, Social Information Processing (SIP) está na abordagem do processamento de informação mais geral, que investiga como o conhecimento é organizado e processado. Sua base está na área denominada cognição social, que emergiu a partir do interesse dos pesquisadores em investigar os processos e mecanismos cognitivos que envolvem os fenômenos psicológicos sociais. Segundo Rodrigues (2004), tem como objetos de estudo, por exemplo, os julgamentos morais, a compreensão do eu (self), a percepção social e o entendimento dos sentimentos, motivos e desejos de si próprio e das pessoas, além do pensamento sobre as instituições sociais. Em termos amplos, refere-se à percepção, aos conceitos e pensamentos em relação ao mundo social.

Dodge (1993) aponta que as ciências do comportamento e sociais podem ser caracterizadas por seu interesse pelo processamento e pela transformação da informação. Salienta ainda o papel central das teorias do processamento da informação em domínios psicológicos importantes, como na descrição dos processos mentais responsáveis por respostas comportamentais mal adaptadas a um estímulo social (por exemplo, uma resposta depressiva à rejeição por alguém amado ou uma resposta agressiva à provocação por um par). Também descreve como a informação em episódios 
comportamentais é transformada em memória nas estruturas do conhecimento que, possivelmente, guiam o processamento futuro e esclarecem a continuidade do comportamento ao longo do tempo. De acordo com essas teorias, a resposta comportamental de uma pessoa a um estímulo situacional ocorre em função de uma sequência de processamento de etapas.

Em relação às crianças, Flavel, Miller e Miller (1999) também salientam que as reações sociais e afetivo-emocionais que manifestam dependem, em parte, de como elas pensam. A qualidade do pensamento das crianças é função do tipo de informação que elas representam em uma dada situação, do modo como operam a informação para atingirem seus objetivos, bem como da quantidade de informação que conseguem ter em mente ao mesmo tempo. Esses autores salientam que o processamento de informação procura oferecer uma compreensão explícita e minuciosa do que o sistema cognitivo de uma criança realmente faz quando está realizando uma tarefa ou em meio a um problema atual. Assim, os modelos do processamento de informação social e suas descrições de como os indivíduos realizam as tarefas servem de base também para compreender como estes interagem com seu ambiente social nas situações do dia a dia.

Embora a utilização de modelos de processamento de informação na explicação do comportamento social remonte às décadas de 1950 e 1960, sua aplicação ao problema da agressão física ocorreu a partir da década de 1980, mais notadamente a partir do esforço de alguns estudiosos: a equipe de Huesmann (1988), por um lado, e Dodge e Crick (1994), por outro. Estes últimos destacaram que os modelos apontam para mecanismos que contribuem para o comportamento socialmente competente das crianças, tendo por base preocupações relacionadas principalmente ao seu ajustamento social, bem como à compreensão dos mecanismos envolvidos na agressividade e no comportamento antissocial.

Huesmann (1988) ofereceu inicialmente um modelo centrado na aprendizagem observacional e, posteriormente, no ano de 1998, propôs o modelo unificado de informação para a agressão. Sua proposta pretende integrar, além de seu modelo anterior, também o modelo proposto por Dodge e Crick (1994).

A abordagem de Dodge (1986) foi inicialmente

188 formulada tendo em vista o ajustamento social em crianças a partir de quatro processos mentais: no primeiro, a criança codifica as pistas situacionais; no segundo, representa e interpreta essas pistas; no terceiro, busca mentalmente possíveis respostas à situação e, no quarto, seleciona e exibe uma resposta. Apoiados em reformulações na própria ciência cognitiva e trazendo inovações conceituais, Dodge e Crick (1994) desenvolveram um modelo mais ampliado, com estrutura cíclica, procurando representar o processamento da informação em paralelo. Propuseram seis passos: a) codificação de pistas internas e externas; b) interpretação e representação mental destas pistas; c) clarificação ou seleção de um objetivo; d) construção ou acesso à resposta; e) decisão da resposta; ef) realização do comportamento.

Como detalha Rodrigues (2005), nos dois primeiros passos a criança codifica e interpreta as pistas sociais oferecidas pelo ambiente, fazendo uma leitura interna da situação social, de acordo as informações disponíveis e armazenadas na memória. No terceiro passo, a criança passa a determinar e selecionar objetivos, metas pessoais e resultados desejados na situação, tendo por base expectativas concretizadas em situações experienciadas no passado. No quarto passo, a criança constrói uma resposta, acessando informações armazenadas na memória, podendo também construir respostas inéditas a novas situações. Já o quinto passo envolve o processo de decisão sobre o que fazer, envolvendo avaliação das respostas e alternativas possíveis, considerando sua adequação e as expectativas quanto aos resultados esperados ou desejados do ponto de vista pessoal, social e moral. Finalmente, no sexto e último passo, tem-se a resposta ou ação comportamental da criança.

O modelo de Dodge e Crick (1994), posteriormente focalizado por Dodge, Salzer, Laird, Pettit e Bates (1999), é apresentado como um modelo cognitivo de tomada de decisão social também influenciado pela emoção. Este ponto foi revisto por Lemerise e Arsenio (2000), que integraram a emoção a cada um dos passos do modelo, ampliando seu poder explicativo. Posteriormente, Dodge e Rabiner (2004), bem como Arsenio e Lemerise (2004), propuseram que a consideração de conceitos de domínio moral também afeta as operações mentais, influenciando a resposta comportamental em situações sociais.

O modelo de Dodge e Crick (1994) vem obtendo expressivo apoio empírico, como demonstrou o estudo 
metanalítico de Vasconcelos, Picon, Prochnow e Gauer (2006). Do ponto de vista aplicado, algumas experiências - tendo o citado modelo como referência, mostram-se bastante interessantes e inovadoras para o contexto escolar/educacional.

\section{Histórias infantis e processamento de informação social}

No plano aplicado, Teglasi e Rothman (2001) desenvolveram um programa voltado para a redução da agressão infantil que associa a leitura e o relato de histórias ao processamento de informação social de Dodge e Crick (1994).

O programa foi desenvolvido em duas escolas elementares norte-americanas, com pequenos grupos heterogêneos de crianças com idades entre 4 e 6 anos, indicadas por professores como agressivas ou não, mediante características de provocação, hostilidade e agressão. Houve pré e pós-avaliação dos professores e os resultados indicaram diminuição de comportamentos antissociais e de externalização nos grupos de crianças identificadas como não agressivas e, entre aquelas consideradas como agressivas.

Um dos objetivos deste programa foi incentivar uma reorganização gradual dos esquemas que governam o processamento de informação e a resolução de problemas sociais com a aprendizagem experiencial. Segundo esses pesquisadores, e também Gayle (2003), tendo em vista que as crianças agressivas têm dificuldade de processar as intenções e motivos de outros, as leituras fornecem um ponto útil para se começar a discussão e verbalização de sentimentos e questões que se apresentaram difíceis para elas. O programa adota a história como uma ferramenta para organizar elementos importantes do processamento de informação social.

Segundo Teglasi e Rothman (2001), com crianças que apresentam comportamento desviante as estratégias de intervenção por meio das narrativas devem ajudar a processar a informação, considerando as pistas sociais em relação às suas experiências prévias, como também informações disponíveis na situação atual.

Os autores descreveram como o programa desenvolvido conjugou aspectos gerais da estrutura da história e os seis passos do processamento de informação social, explanados a seguir:
1. O que está acontecendo? Os autores apontam que as crianças identificam o problema avaliando o que está acontecendo no mundo exterior sob a perspectiva do ameaçador, da vítima e do espectador. A observação e interpretação das pistas sociais são enfatizadas ao discutir o que está acontecendo em uma cena particular da história.

2. O que os personagens estão pensando e como eles estão se sentindo? Apontam como as crianças consideram as circunstâncias externas e como identificam o problema, observando o"mundo interno" de cada personagem, explorando a relação entre sentimentos, intenções e interpretações da situação externa dos personagens.

3. Quais são as intenções emetas dos personagens? Salientam como os pensamentos e sentimentos dos personagens sobre uma situação particular podem ser discutidos com relação a seus objetivos e intenções no momento e por um longo prazo, incentivando as crianças a esclarecerem suas próprias intenções e objetivos enquanto consideram as vivências dos personagens.

4. Oque os personagens alcançam com suas ações? Os autores observam que os resultados reais e prováveis das decisões, de planos e ações dos personagens podem ser discutidos em relação a seus objetivos e intenções. As crianças são guiadas a considerar várias ações possíveis, de acordo com os objetivos e intenções dos personagens, distinguindo entre as ações que resolvem o problema somente no momento e as estratégias que geram soluções a longo prazo.

5. Como os personagens executam e monitoram seus comportamentos? Os autores apontam como os personagens podem realizar a ação pretendida eficazmente ou em vão; as razões são observadas e discutidas.

6. Quais são as lições aprendidas? Teglasi e Rothman (2001) assinalam que "a solução de problemas efetiva requer a aplicação de lições de vida que são naturalmente aprendidas a partir da experiência" (p.77). O programa tenta ampliar este processo, delineando lições em geral dos detalhes da história, relacionando-as às interações do grupo e às experiências individuais.

Embora tenham encontrado resultados satisfatórios em relação ao desenvolvimento das crianças, e as narrativas utilizadas tenham se apresentado como 
um recurso adequado a ser explorado como estratégia na prevenção de problemas de comportamento infantil, não houve resultados voltados especificamente para as histórias utilizadas no desenvolvimento do programa. Uma investigação mais específica das narrativas, considerando os resultados positivos que elas possibilitaram alcançar na intervenção com escolares estadunidenses, faz-se necessária, sobretudo no caso de se aplicar programa semelhante no contexto brasileiro.

Diante do exposto, este estudo objetivou analisar uma amostra de livros de histórias infantis nacionais, com foco no modelo de processamento de informação social, visando a oferecer subsídios para sua utilização posterior na promoção do desenvolvimento socio-cognitivo em crianças pré-escolares.

\section{Método}

\section{Amostragem}

A amostra foi constituída por cem livros de histórias infantis nacionais. Para a seleção dessa amostra foi consultado o catálogo de livros infantis da Secretaria de Estado de Educação de Minas Gerais, classificados por faixa etária/tipo de leitor (leitor iniciante, com alguma experiência, com experiência). Paralelamente, fez-se um levantamento de livros junto a seis editoras de literatura infantil de renome nacional. Embora o critério de faixa etária não deva ser rígido, pois é preciso considerar que cada leitor tem sua própria maturidade para leitura, essa questão foi importante no trabalho a fim de permitir uma adequação da amostra à proposta da pesquisa. Visando também atender/considerar os critérios de qualidade e recomendação dos livros, gerou-se, deste modo, uma listagem mestre que norteou a avaliação dos pesquisadores para uma seleção randômica de cem livros nacionais. As narrativas selecionadas apresentavam em média vinte páginas, todas ricamente ilustradas e coloridas, com temáticas variadas, de acordo com a idade e os interesses da criança pré-escolar.

Os livros foram adquiridos, e foi realizada, primeiramente, uma leitura inicial. Posteriormente, procedeu-se a uma nova leitura, para análise do conteúdo das narrativas conjugado aos componentes do processamento de informação social, com base nos passos do modelo SIP (Dogde \& Crick, 1994) propostos na estrutura do programa desenvolvido porTeglasi e Rothman (2001). Para essa análise, foram elaborados dois instrumentos. O primeiro foi utilizado para registrar quais componentes do programa apareciam nas diferentes partes das narrativas (início, meio e fim) e incluiu uma escala geral de avaliação do livro, envolvendo o número de componentes presentes e passíveis de serem explorados na narrativa (Tabela 1).

O segundo instrumento foi elaborado visando facilitar o registro do aparecimento dos componentes do programa proposto por Teglasi e Rothman (2001), considerando cada página do livro (Tabela 2).

Os dados foram obtidos por meio de uma análise criteriosa, baseada no processamento de informação social, que foi realizada com a leitura detalhada de cada livro em conjunto pela pesquisadora e as bolsistas de iniciação científica envolvidas, a fim de obter a maior concordância possível quanto ao aparecimento, na narrativa, de cada componente do programa proposto por Teglasi e Rothman (2001). Concomitantemente a essa leitura, os dados foram codificados ao longo da narrativa por meio das perguntas anteriormente explicitadas: 1) Oqueestáacontecendo?2) Oqueos personagens estão pensando e o que estão sentindo? 3) Quais as intenções e metas dos personagens? 4) O que os personagens estão alcançando com suas ações? 5) Como os personagens executam e monitoram suas ações? e 6) Quais são as lições aprendidas pelos personagens?

Considerou-se, nesta análise, a ocorrência de pistas internas e externas, representadas respectivamente pelos termos que denotavam estados mentais presentes na narrativa e pelas expressões faciais, formas e gestos observados nas ilustrações. A análise dos termos que denotavam estados mentais foi feita a partir de duas listas geradas por meio da revisão bibliográfica dos estudos internacionais de Bretherton e Beeghly (1982) e Dyer et al. (2000). Da combinação dessas listas obteve-se uma única listagem, dividida em quatro categorias: termos emocionais, cognitivos, desejos/intenções e avaliação moral/obrigação, definidas de acordo com Dyer et al. (2000). Esta listagem serviu como base para a codificação dos termos mentais encontrados nos livros, e foi utilizada como critério de discussão das discordâncias. Avaliou-se, também, o planejamento do personagem e suas intenções, a realização ou não de seus objetivos (propostos na narrativa) e as lições explícitas aprendidas por ele. 
Tabela 1. Instrumento de avaliação do livro por partes da narrativa. Juiz de Fora (MG), 2006.

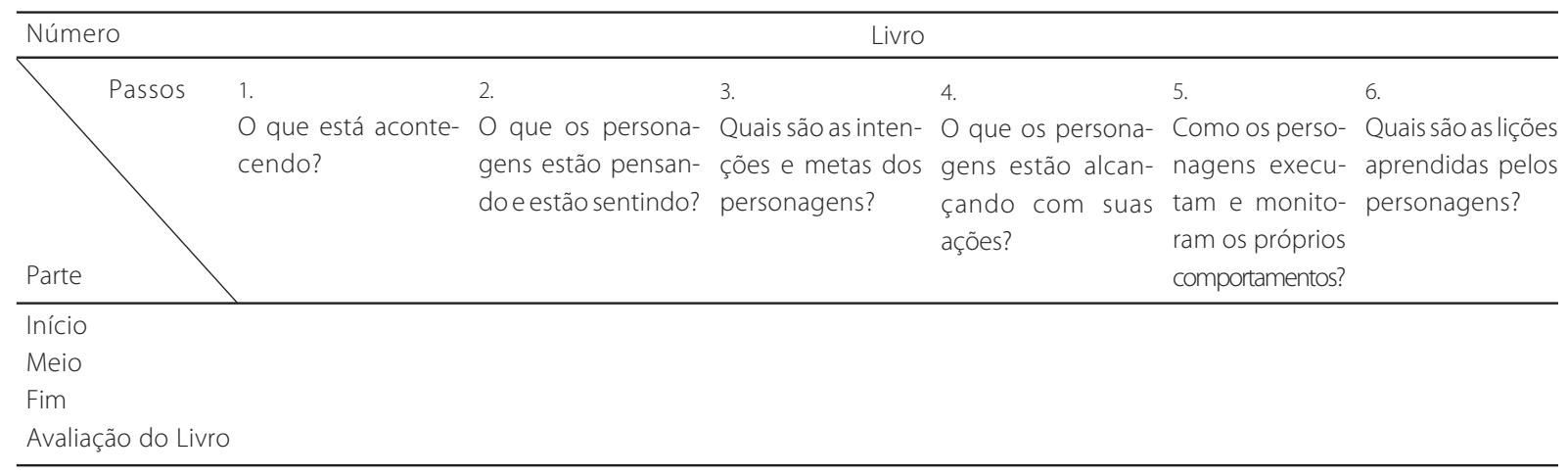

Nota: Passos inspirados no modelo de SIP (Dodge \& Crick, 1994) propostos por Teglasi e Rothman (2001).

\section{ESCALA DE AVALIAÇÃO DO LIVRO COM BASE EM TEGLASIE ROTHMAN (2001)}

1) Narrativa muito curta (inviabiliza análise com base no modelo SIP).

2) Escasso repertório de pistas, contemplando apenas um passo do modelo do processamento de informação social.

3) Limitado repertório de pistas sociais, contemplando dois passos do modelo SIP.

4) Repertório relevante de pistas sociais, contemplando 3 ou 4 passos do modelo SIP.

5) Repertório significativo de pistas sociais, contemplando cinco passos do modelo SIP.

6) Narrativa rica em pistas sociais, contemplando todos os passos do modelo SIP.

Tabela 2. Instrumento de avaliação do livro por página. Juiz de Fora (MG), 2006.

\begin{tabular}{|c|c|c|c|c|c|c|}
\hline \multirow[t]{2}{*}{ Número } & \multicolumn{6}{|c|}{ Livro } \\
\hline & 1. & 2. & 3. & 4. & 5. & 6. \\
\hline & $\begin{array}{l}\text { O que está aconte- } \\
\text { cendo? }\end{array}$ & $\begin{array}{l}\text { O que os persona- } \\
\text { gens estão pensan- } \\
\text { do e estão sentido? }\end{array}$ & $\begin{array}{l}\text { Quais são as inten- } \\
\text { ções e metas dos } \\
\text { personagens? }\end{array}$ & $\begin{array}{l}\text { O que os persona- } \\
\text { gens estão alcan- } \\
\text { çando com suas } \\
\text { ações? }\end{array}$ & $\begin{array}{l}\text { Como os perso- } \\
\text { nagens execu- } \\
\text { tam e monito- } \\
\text { ram os próprios }\end{array}$ & $\begin{array}{l}\text { Quais são as lições } \\
\text { apreendidas pe- } \\
\text { los personagens? }\end{array}$ \\
\hline
\end{tabular}

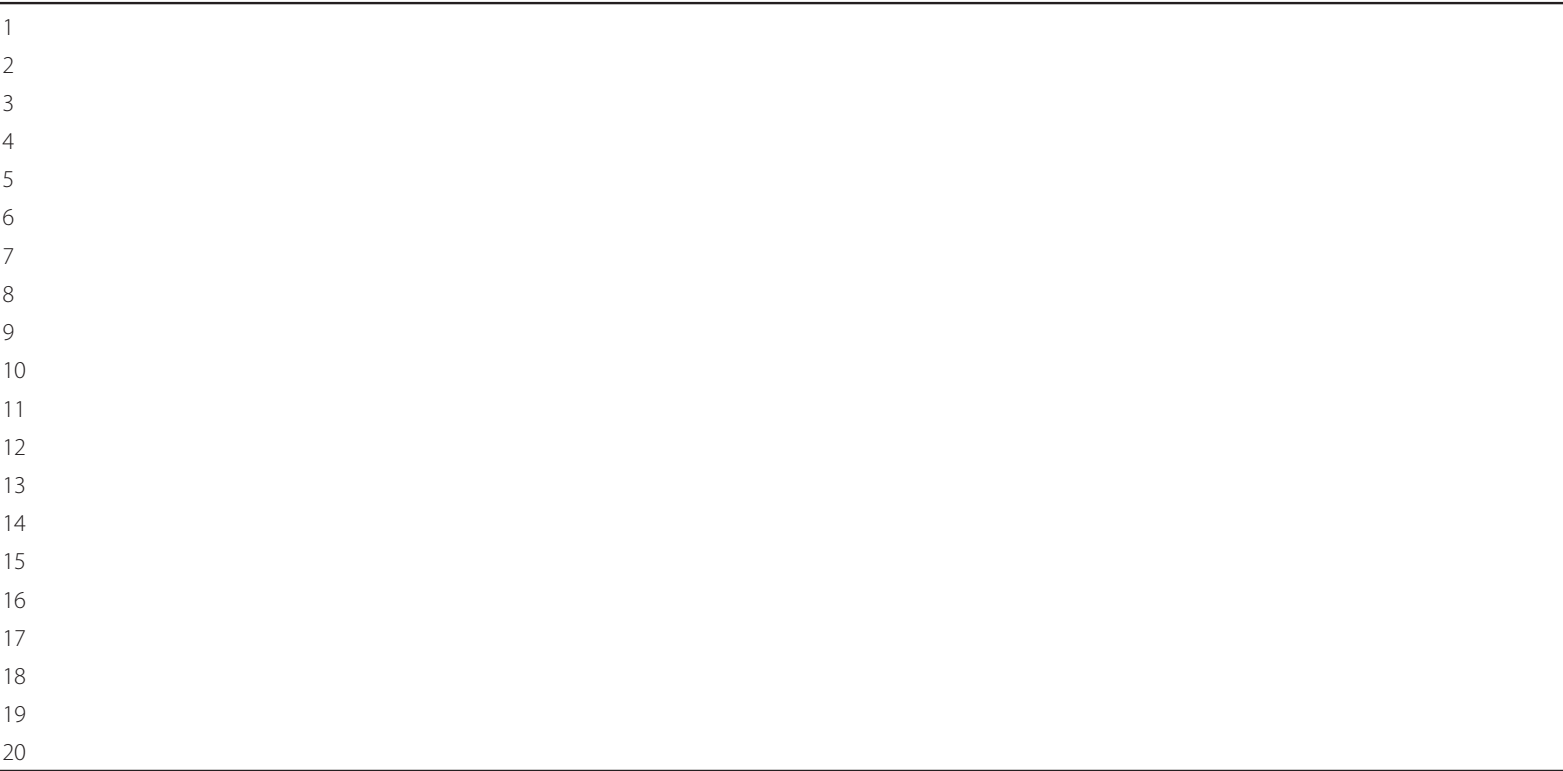


Finalmente, verificou-se o número de passos atendidos pela narrativa, considerando-se os seguintes critérios de análise: livros que continham apenas um componente do modelo foram descritos como pouco adequados para o trabalho com foco no processamento de informação social; aqueles que atendiam a dois componentes foram considerados com limitado repertório de pistas sociais; e livros que apresentaram três ou quatro componentes do modelo foram avaliados com número relevante de pistas sociais. Por fim, as narrativas que contemplaram cinco ou todos os passos do modelo foram consideradas ricas do ponto de vista do processamento de informação social.

\section{Resultados e Discussão}

A análise dos livros nacionais com base no modelo do processamento de informação social indicou resultados bastante satisfatórios, considerando o conteúdo da narrativa e o atendimento aos componentes propostos porTeglasi e Rothman (2001).

Em relação aos resultados apontados (Tabela 3), observa-se que dos cem livros analisados, todos contemplaram algum desses componentes; não foi encontrada nenhuma narrativa muito curta, que inviabilizasse a análise com base no processamento de informação social. No conjunto, é expressiva a porcentagem de livros infantis (74\%) que apresentaram elevado repertório de pistas sociais (ou seja, contemplaram quatro, cinco ou seis dos componentes do programa), o que permite indicar, no contexto nacional, a possível utilização dessas narrativas pelo psicólogo escolar, considerando a vertente preventiva e promotora de competências cognitivas, como foi realizado por Teglasi e Rothman (2001).
É relevante destacar que, na análise dessa amostra, 96\% e $91 \%$ dos livros viabilizavam trabalhar com as crianças os aspectos voltados para a situação social ( $O$ que está acontecendo?) e desenvolvimento e compreensão de estados mentais ( $O$ que os personagens estão pensando e sentindo?), respectivamente. Os dados acima conver-gem com o elevado número de termos mentais (1 245 termos) referentes à emoção e cognição encontrados em parte integrante desta pesquisa (Rodrigues, Oliveira, Rubac \& Tavares, 2006). Coadunam-se também com as pistas externas representadas por figuras e observadas no texto por meio de expressões faciais, formas e gestos. Nessa perspectiva, Teglasi e Rothman (2001) salientam que as ilustrações das histórias são importantes e passíveis de serem exploradas ao longo da narrativa, pois auxiliam a criança a identificar e avaliar o problema em relação ao mundo externo, observar pistas sociais e, em relação ao mundo interno (de cada personagem), explorar seus sentimentos e pensamentos. Tais aspectos permitem caracterizar essa amostra de livros infantis como potencialmente fértil para a promoção do desenvolvimento sociocognitivo infantil.

Dos cem livros, $71 \%$ contemplaram o terceiro componente do programa, que focaliza intenções e metas dos personagens, possibilitando o trabalho de aspectos importantes com as crianças que apresentam viéses e distorções cognitivas - como as agressivas (Dodge \& Crick, 1994; Z. A. Del Prette \& A. Del Prette, 2005). A presença expressiva de aspectos relacionados ao planejamento e à intencionalidade nas narrativas analisadas pode favorecer a construção do conhecimento e a compreensão sobre as pessoas e suas ações. Esta compreensão, como destaca Alves (2001), permite que as crianças tenham suas tendências hostis e impulsos antissociais atenuados pela satisfação que conseguem obter com o desfecho da história.

Tabela 3. Frequência e porcentagem relativas aos componentes propostos por Teglasi e Rothman (2001) ( $n=100)$. Juiz de Fora (MG), 2006.

\begin{tabular}{lcc}
\hline Categorias & Frequência $(f)$ & Porcentagem $(\%)$ \\
\hline 1. Escasso repertório de pistas sociais (contempla apenas 1 componente) & 3 & 3 \\
2. Limitado repertório de pistas sociais (contempla 2 componentes) & 6 & 6 \\
3. Repertório relevante de pistas sociais (contempla 3 ou 4 componentes) & $32(17+15)$ & 32 \\
4. Repertório significativo de pistas sociais (contempla 5 componentes) & 47 & 47 \\
5. Narrativa rica em pistas sociais (contempla todos os componentes) & 12 & 12 \\
\hline Total & 100 & 100 \\
\hline
\end{tabular}


Vale ressaltar, ainda, que os dados levantados em relação ao quarto (70\%) e quinto itens do programa (81\%), que envolvem questionamento sobre as estratégias encontradas pelos personagens, bem como a execução e o monitoramento de suas ações e comportamentos, acentuam a viabilidade de se trabalhar com as crianças alternativas de ação em situação de conflito, pois, como afirma Alves (2001), as histórias oferecem oportunidades para as crianças ampliarem seus conhecimentos sobre o mundo social, reproduzindo contextos e valores culturais. Entretanto, como pode ser observado na Tabela 1, somente 12\% dos livros evidenciaram, de forma explícita, os seis componentes do modelo, indicando que essa amostra de livros favorece pouco, pelo menos do ponto de vista explícito, a ampliação do processo de delineamento pelas crianças de lições da história relacionadas às interações em grupo e às experiências individuais.

Os resultados aqui obtidos fornecem subsídios importantes para a prática de psicólogos escolares brasileiros e outros profissionais interessados no desenvolvimento sociocognitivo e prevenção de comportamentos agressivos em crianças pré-escolares. De modo geral, os resultados aqui obtidos reforçam as premissas de Teglasi e Rothman (2001), relacionadas à articulação entre a leitura de histórias e processamento de informação social.

\section{Considerações Finais}

O modelo de prevenção primária em saúde mental, que envolve ações que propiciam o bem-estar e o desenvolvimento das potencialidades dos indivíduos, incentiva a reflexão e a busca de novas formas de intervenção psicológica mais proativas.

Nessa perspectiva, embora este estudo não constitua uma proposta de intervenção, os resultados gerados a partir da análise de livros infantis nacionais sob o enfoque do processamento de informação social corroboram estudos internacionais, fornecendo subsídios para a implementação de práticas psicológicas mais inovadoras e diversificadas no âmbito preventivo.

Os resultados aqui apresentados indicam a viabilidade da utilização dos livros infantis nacionais como recurso cognitivo para a promoção do desenvolvimento sociocognitivo e a prevenção de compor- tamentos agressivos e antissociais. Mais especificamente, a amostra de livros nacionais aqui analisada constitui um rico e útil recurso, que pode ser utilizado em programas a serem desenvolvidos no contexto educacional brasileiro, seja pelo psicólogo escolar/ educacional ou por professores de educação infantil, que devem ser capacitados no âmbito da leitura como prevenção de problemas.

Nesse sentido, é preciso destacar a necessidade de se realizar com os professores um trabalho participativo de análise crítica e criativa, contextualizado em termos psicossociais, que leve à possibilidade de prevenção e estimulação do desenvolvimento da criança por meio de discussões dirigidas, que envolvam personagens e situações oferecidas pela literatura infantil. Atenção específica deve ser conferida pelo psicólogo às etapas que compõem essa atividade, como a análise e seleção dos livros e, sobretudo, à ação mediadora do professor que, muitas vezes, desconhece as ricas possibilidades de exploração sociocognitiva do conteúdo das narrativas.

É oportuno salientar que o trabalho não se restringe à escola, podendo ser implementado em outros contextos de atividades dos profissionais da psicologia, por exemplo, as clínicas-escolas. Todavia, considerando a carência de pesquisas e relatos de experiências envolvendo o tema, ressalta-se a necessidade de acompanhamento sistemático e da realização de investigações a fim de que possam ser dimensionados seus efeitos e suas reais implicações sobre o desenvolvimento e comportamento infantis.

\section{Referências}

Alves, J. M. (2001). Histórias em quadrinhos e educação infantil. Psicologia: Ciência e Profissão, 21 (3), 2-9.

Araújo, C. M., \& Almeida, S. F. (2003). Psicologia escolar institucional: desenvolvendo competências para uma atuação relacional. In S. F. Almeida (Org.), Psicologia escolar:ética e competência na formação e atuação profissional (pp.59-82). Campinas: Alínea.

Arsenio, W. F., \& Lemerise, E. A. (2004). Aggression and moral development: Integrating social information processing and moral domain models. Child Development, 75 (4), 987-1002.

Becker, C. D. (2001). História da literatura infantil brasileira. In J. A. Saraiva (Org.), Literatura e alfabetização: do plano do choro ao plano da ação (pp.35-41). Porto Alegre: Artmed. 
Bretherton, I., \& Beeghly, Y. (1982). Talking about internal states: the acquisition of an explicity Theory of Mind. Developmental Psychology, 18 (6), 906-921.

Cassidy, K. W., Ball, L. V., Rourke, M. T., Wermer, R. S., Feeny, N., Chu, J. Y., et al. (1998). Theory of mind concepts in children's literature. Applied Psycholinguistics, 19 (2), 463-470.

Del Prette, A., \& Del Prette, Z. A. (2003). Aprendizagem socioemocional na escola e prevenção da violência: questões conceituais e metodologia da intervenção. In A. Del Prette \& Z. A. Del Prette (Orgs.), Habilidades sociais, desenvolvimento e aprendizagem: questões conceituais, avaliação e intervenção (pp.83-127). Campinas: Alínea.

Del Prette, Z. A., \& Del Prette, A. (2005). Psicologia das habilidades sociais na infância: teoria e prática. Petrópolis: vozes.

Dodge, K. A. (1986). A social information processing model of social competence in children. In M. Perlmutter (Org.), Minnesota symposium in child psychology. Cognitive perspectives in children's social and behavioral development, 18 (pp.77-125). Hillsdale, New Jersey: Erlbaum.

Dodge K. A. (1993). Social-cognitive mechanisms in the development of conduct disorder and depression. Annual Review of Psychology, 44 (1), 559-584.

Dodge, K. A., \& Crick, N. R. (1994). A review and reformulation of social information-processing mechanisms in children's social adjustment. Psychological Bulletin, 115 (1), 74-101.

Dodge, K. A., Salzer B. V., Laird, R. D., Pettit, G. S., \& Bates, J. E. (1999). Knowledge structures, social information processing, and children's aggressive behavior. Social Development, 8 (2), 220-236.

Dodge, K. A., \& Rabiner, D. V. (2004). Returning to roots: on social information processing and moral development. Child Development, 75 (4), 1003-1008.

Dyer, J. R., Shatz, M., \&Wellman, H. M. (2000). Young children's storybooks as a source of mental state information. Cognitive Development, 15 (1), 17-37.

Elias, L. C. (2003). Solução de problemas interpessoais em crianças com baixo rendimento escolar. Tese de doutorado não-publicada, Faculdade de Filosofia, Ciências e Letras, Universidade de São Paulo, Ribeirão Preto.

Elias, L. C., \& Marturano, E. M. (2005). Oficinas de linguagem: proposta de atendimento psicopedagógico para crianças com queixas escolares. Estudos de Psicologia (Natal), 10 (1), 53-61.

Feldman, N. (1994). De prevención a promoción: un desafio latinoamericano. In Proceedings of 17 th International School Psycology Colloquium e $2^{\circ}$ Congresso Nacional de Psicologia Escolar (pp. 85-88). Campinas: PUC-Campinas.
Flavel, J. H., Miller, P. H., \& Miller, A. S. (1999). Desenvolvimento cognitivo. Porto Alegre: Artmed.

Gayle L. M. (2003). Bullying and teasing: social powerinchildren's groups. New York: Springer.

Guzzo, R. S. (2003). Saúde psicológica, sucesso escolar e eficácia da escola: desafios do novo milênio para a psicologia escolar. In Z. A. Del Prette (Org.), Psicologia escolar eeducacional: saúde equalidade de vida (pp.25-42). Campinas: Alínea.

Huesmann, L. R. (1988). An information processing model for the development of aggression. Aggressive Behavior, $14(1), 13-24$.

Lemerise, E. A., \& Arsenio, W. F. (2000). An integrated model processes and cognition in social information processing. Child Development, 71 (1), 107-118.

Rodrigues, M. C. (2004). Concepções docentes pré-escolares sobre teorias da mente e sociocognitivas aplicadas. Tese de doutorado não-publicada, Pontifícia Universidade Católica de Campinas.

Rodrigues, M. C. (2005). Prevenção na escola: um enfoque cognitivo-social. In M. M. P. E. Mota (Org.), Psicologia: Interfaces com a educação e a saúde (pp.11-30). Juiz de Fora: Editora UFJF.

Rodrigues, M. C., Abreu C., \& Carvalho, C. G. (2005). Histórias infantis e prevenção da agressividade: um enfoque cognitivo. Revista Brasileira de Extensão Universitária/Fórum de Pró-Reitorias de Extensão, 3 (2), 62.

Rodrigues, M. C., Oliveira, P. A., Rubac, J. S., \& Tavares, A. L. (2006). Histórias e desenvolvimento infantil: contribuições a partir da teoria da mente e do processamento de informação social. Anais da XXXVI Reunião Anual da Sociedade Brasileira de Psicologia, Salvador, BA.

Saraiva, J. A. (2001). A situação da leitura e a formação do leitor. In J. A. Saraiva (Org.), Literatura e alfabetização: do plano do choro ao plano da ação (p.23-27). Porto Alegre: Artmed.

Teglasi, H., \& Rothman, L. (2001). Stories: a classroom-based program to reduce aggressive behavior. Journal of School Psychology, 39 (1), 71-94.

Vasconcelos, S. J. L., Picon, P., Prochnow, L. P., \& Gauer, G. J. C. (2006). O processamento das informações sociais em crianças e adolescentes. Estudos de Psicologia (Natal), 11 (3), 275-279

Witter, G. P. (2004). Leitura e psicologia. Campinas: Alínea.

Recebido em: 11/4/2007

Versão final reapresentada em: 31/10/2007

Aprovado em: 8/1/2008 